\title{
IMPLEMENTATION FRAMEWORK OF GREEN BUILDING FOR GOVERNMENT BUILDING: MENARA KERJA RAYA, MALAYSIA
}

\author{
Shiela Sharif ${ }^{1,2}$, Syahrul Nizam Kamaruzzaman ${ }^{2}$, Michael Pitt ${ }^{3}$ \\ ${ }^{1}$ Department of Building Surveying, Faculty of Built Environment, University of Malaya, \\ Kuala Lumpur, Malaysia \\ ${ }^{2}$ Public Works Department of Malaysia, Jalan Sultan Salahuddin, Kuala Lumpur, Malaysia \\ ${ }^{3}$ University College London, London, United Kingdom
}

E-mails:shiela@jkr.gov.my,syahrulnizam@um.edu.my,michael.pitt@ucl.ac.uk

\begin{abstract}
The purpose of this study is to develop the implementation of the framework of the government green building (GB) project in Malaysia. The research intended to investigate the factors involved in the development of the framework and significant relationships that exist among the factors. A total of 30 respondents were selected from Menara Kerja Raya (MKR) project team that included engineers, assistant engineers, technical assistant, stakeholders, contractors, and consultants. The pilot test analysis was conducted using the quantitative analysis and hypothesis testing through SPSS 22.0. In conclusion, the 'types of project execution' was the main factor to make the successful delivery of the GB projects followed by project management and policies guidelines, project staff perceptions, and the government policies. This framework would contribute to the existence of the GB implementation as well as serve as a basic platform for efficient and systematic execution of its projects in Malaysia. It is hoped that the implementation of this framework could promote the success of GB delivery, especially to the Malaysian government projects.
\end{abstract}

Keywords: Green Building, Green Building Design, Framework Implementation, Government Building, Menara Kerja Raya

\section{INTRODUCTION}

Malaysia is a developing country with rapid development and industrialisation, which heavily reliant on energy resulting in a significant increase greenhouse gas (GHG) emissions. Kamaruzzaman et al. (2016) reported that the percentage of energy demand estimated for 2015 for the residential and commercial buildings contributed about $18.1 \%$ as well as the average annual growth rate, which was as high as $16.4 \%$. Besides, Begum \& Pereira (2011) also reported that the commercial buildings alone in Malaysia were accounted a fifth of the total domestic energy consumption. Hence, it was the commercial buildings that highly required energy consumption and contributed to the $\mathrm{CO}_{2}$ emissions.

In addition, Kamaruzzaman et al. (2016) also forecasted that the energy consumption and $\mathrm{CO}_{2}$ emissions in the building sector may increase annually. Nowadays, over $40 \%$ of GHG emissions are accredited to the existing buildings and surrounding communities as reported by many researchers (Shika et al.,2010). The percentage of GHG emission is expected to increase annually up to $12.1 \%$ by 2020. Therefore, the Malaysian government has begun to execute the new strategy and policies in order to reduce GHG emissions by 2020 .

The buildings where citizens live, work, and play interact with the surrounding environment by affecting storm water runoff, and energy and water consumptions, transportation patterns, and indoor air quality (Adetokunbo, \& Emeka, 2015). Recognising the role of the buildings in the environment has led to significant efforts to design, build, and maintain more sustainable structures (Thomas, 2007). GB practices include environmental responsibility and resource efficient by promoting the practices of conserving energy and water resources, preserving open spaces, minimising the emission of toxic substances, sustaining and improving the quality of human life, and maintaining the capacity of the ecosystem at the local and global levels. The benefits of GB to the environment are energysaving at $24 \%$ up to $50 \%, \mathrm{CO}_{2}$ emissions $33 \%$ up to $39 \%$, water-saving $40 \%$, and solid waste reduction of $70 \%$ for each GB (Turner \& Frankes, 2008). GB could help to enhance the tenants' health and productivity by reducing environmental impact, using materials effectively, and minimising electric and water 
utility costs, which give long term economic return (Vyas \& Jha, 2017).

The Green Building Index (GBI) has been proposed as the rating tool for GB and private initiatives since 2009 in Malaysia. It is a benchmarking rating system that incorporates international recognition of the best practice in environmental design and performance for GB projects in Malaysia despite the excellent and best practice of project management procedures and guidelines implemented by PWD Malaysia. For example, the Menara Kerja Raya (MKR), which was successfully developed as a GB, was one of the projects implemented by PWD Malaysia and achieved the GBI full energy efficiency points of Building Energy Index (BEI) for office buildings of about 90
$\mathrm{kWh} / \mathrm{m}^{2} /$ year (Moghimi et al., 2014; Building Management Data, MKR Maintanence Team, 2017) as illustrated in Figure 1. Furthermore, MKR was chosen as the case study to be developed as the new framework implementation of GB in Malaysia due to its excellent recognition as the first government building to receive the GBI Platinum Award in June 2016 (GBI, 2017; The Star, 2016) and could be used as the major reference for GB area. Besides that, this work is a benchmark for PWD Malaysia as the implementer of GB projects in Malaysia. This study was set out to establish the factors involved in the development of the framework implementation of GB designs for the Malaysian government buildings. The analysis was determined based on quantitative research and hypothesis testing.

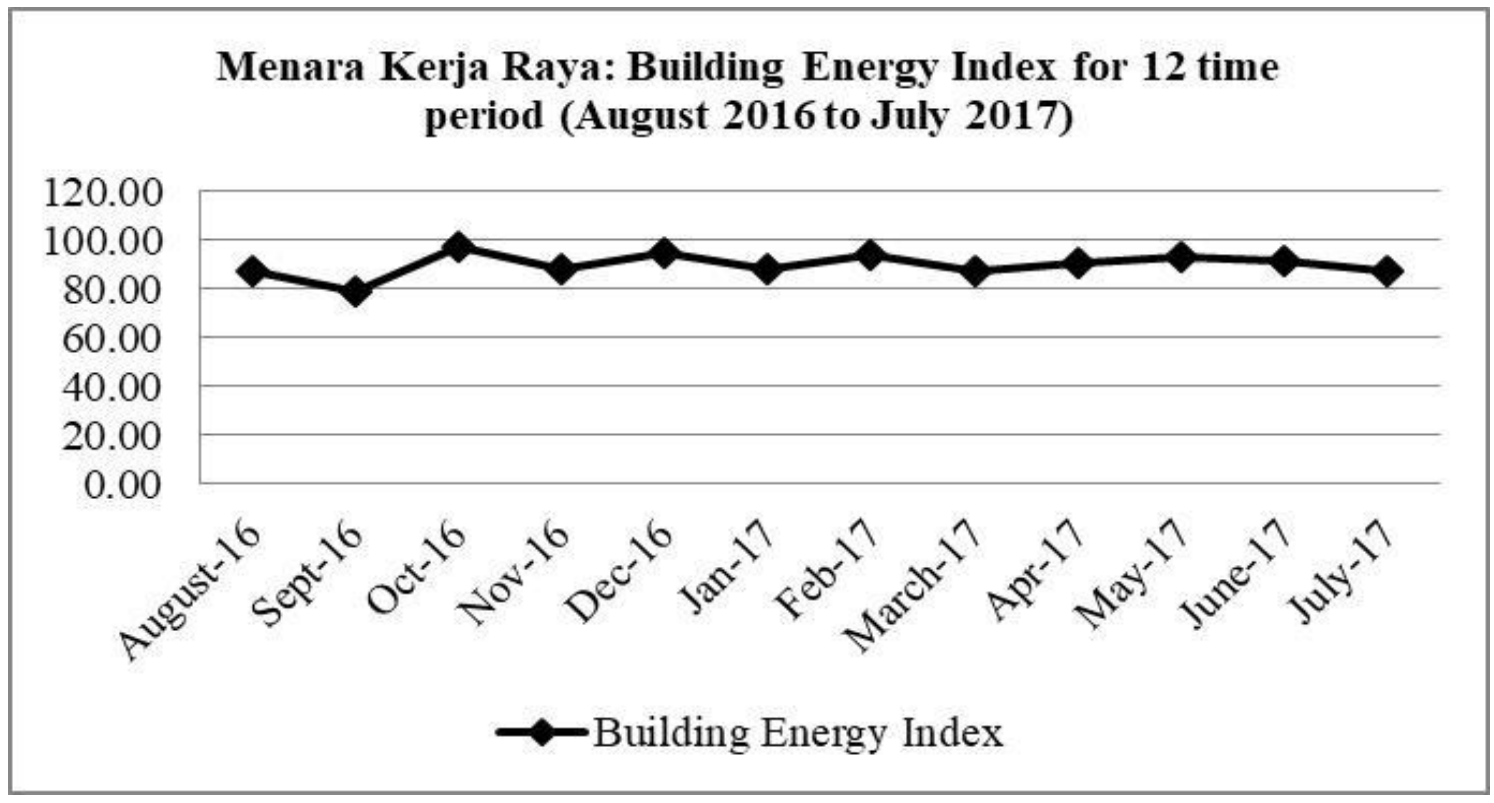

Figure 1 Building Energy Index for 12 time period

(Data source: Building Management Data, MKR Maintanence Team, 2017)

\section{PROBLEM IDENTIFICATION}

The Prime Minister of Malaysia, Dato' Sri Mohd Najib Tun Abdul Razak announced the Malaysian commitment in the United Nations Climate Change Congress 2009 (COP-21) in Copenhagen on 17 December 2009 that by 2020 Malaysia will have reduced carbon emission rate up to $40 \%$ from the current rate in 2005. It is more challenging when Malaysia has become the net importer of energy since 2015 . The way Malaysian building has been designed will affect the energy consumption required. Therefore, it is difficult to justify the implementation of GB in the government projects. Existing guidelines and code of practice on energy efficiency (EE) and renewable energy (RE) to achieve low carbon building in the market such as the Malaysian Standard Energy Efficiency and Use of Renewable Energy for Non-Residential
Buildings - Code of Practice (MS 1525:2014), Dasar Teknologi Hijau, and development and publication of $\mathrm{EE}$ do not cover the strategies or method to implement GB for the government projects.

In order to ensure that the development of GB is successfully implemented, Horman et al. (2006) recommended that the processes involved should be highlighted. However, the development of GB to date is still ineffective, especially the government buildings in Malaysia. Throughout the critical analysis on the GB trends for worldwide by Darko \& Chan (2016), Malaysia was not listed among the countries which contribute or promote the GB research from 1990 until 2015 (as of the end of August). It indicates that the awareness of GB projects in Malaysia is still limited, which implies the need to study and further 
investigation in the area. The factors influencing the framework implementation of GB in Malaysia are yet to be identified in the literature. Therefore, detailed research is needed to identify the significant factors related to the delivery performance of GB projects.

\section{LITERATURE REVIEW}

GB refers to a structure and uses a process that is environmentally responsible and resourceefficient throughout the life cycle of a building; from siting to design, construction, operation, maintenance, renovation, and demolition. This practice expands and complements the classical building design that concerns economy, utility, durability, and comfort. Although new technologies are constantly being developed to complement the current practices in creating greener structures, the common objective is that GB are designed to reduce the overall impact of the built environment on the human health and natural environment by:

i. Using energy, water, and other resources efficiently;

ii. Protecting occupant health and improving employee productivity; and

iii. Reducing waste, pollution, and environmental degradation

A similar concept is natural building, which is usually on a smaller scale and tends to focus on the use of natural materials that are available locally. Other related topics include sustainable design and green architecture. GB does not specifically address the issue of the retrofitting existing homes.

\section{GOALS OF GREEN BUILDING}

The concept of sustainable development could be traced to the energy (especially fossil oil) crises and environmental pollution concern in the 1970s. There are a number of GB motives, including environmental, economic, and social benefits. However, modern sustainability initiatives call for an integrated and synergistic design to both the new construction and retrofitting of an existing structure. Also known as sustainable design, this approach integrates the building life cycle with each green practice employed with a design-purpose to create a synergy amongst the practices used. GB brings together a vast array of practices and techniques to reduce and ultimately eliminate the impacts of new buildings on the environment and human health. It often emphasises on taking advantage of renewable resources; e.g., using sunlight through passive and active solar, photovoltaic techniques, and plants and trees through green roofs, rain gardens, and reducing rainwater runoff.

While the practices or technologies employed in GB are constantly evolving and may differ from one region to another, there are fundamental principles that persist from which the method is derived; siting and structure designing, energy, water, and material efficiencies, indoor environmental quality enhancement, operations and maintenance optimisation, and waste and toxics reduction. With the proper synergistic design, individual GB technology may also work together to produce a greater cumulative effect.

\section{SITING AND STRUCTURE DESIGN EFFICIENCY}

The concept stage, in fact, is one of the major steps in a project life cycle as it has the largest impact on cost and performance. In designing environmentally optimal buildings, the objective is to minimise the total environmental impact associated with all life cycle stages of the building project. However, building as a process is not as streamlined as an industrial process, varies from one building to the other, and never repeats itself identically. In addition, buildings are much more complex products composed of a multitude of materials and components, in which each constitutes various design variables to be decided at the designing stage. A variation of every design variable may affect the environment during all the relevant life cycle stages of the building.

\section{ENERGY EFFICIENCY (EE)}

GB often includes measures to reduce energy use. To increase the efficiency of the building envelope (the barrier between conditioned and unconditioned space), high-efficiency windows and insulation in walls, ceilings, and floors may be used. Another strategy that is the passive solar building design is often implemented in low-energy homes. Designers orient windows and walls and place awnings, porches, and trees to shade windows and roofs during the summer while maximising solar gain in the winter. In addition, effective window placement (day lighting) can provide more natural light and lessen the need for electric lighting during the day. Solar water heating reduces energy costs further. Onsite generation of renewable energy through the solar, wind or hydro power or biomass can significantly reduce the environmental impact of the building. Power generation is generally the most expensive feature to add to a building. 


\section{WATER EFFICIENCY}

Reducing water consumption and protecting water quality are key objectives in sustainable building. One critical issue of water consumption is that in many areas, the demands on the supplying aquifer exceed its ability to replenish itself. To the maximum feasible extent, facilities should increase their dependence on water that is collected, used, purified, and reused on-site. The protection and conservation of water throughout the life of a building may be accomplished by designing dual plumbing that recycles water for toilet flushing. Waste-water may be minimised by utilising conserving water fixtures such as ultralow flush toilets and low-flow shower heads. Besides that, point of using and heating water treatment improves both water quality and $\mathrm{EE}$ while reducing the amount of water in circulation. The use of non-sewage and grey water for on-site use such as site-irrigation will minimise demands on the local aquifer.

\section{MATERIALS EFFICIENCY}

Building materials typically considered to be green include rapidly renewable plant materials like bamboo (because bamboo grows quickly) and straw, lumber from forests certified to be sustainably managed, insulated concrete forms, dimension and recycled stone, recycled metal, and other products that are non-toxic, reusable, renewable, and/or recyclable (e.g., trass, linoleum, sheep wool, panels made from paper flakes, compressed earth block, adobe, baked and rammed earth, clay, vermiculite, flax linen, sisal, sea grass, cork, expanded clay grains, coconut, wood fibre plates, calcium sand stone, and concrete (high and ultra-high performance and roman self-healing concrete). The Environmental Protection Agency (EPA) also suggests using recycled industrial goods such as coal combustion products, foundry sand, and demolition debris in construction projects. Building materials should be extracted and manufactured locally to the building site to minimise the energy embedded in their transportation. Building elements should be manufactured off-site and delivered to wherever possible sites to maximise the benefits of offsite manufacture including minimising waste, maximising recycling, highquality elements, and less noise and dust.

\section{INDOOR ENVIRONMENTAL QUALITY ENHANCEMENT}

The Indoor Environmental Quality (IEQ) category in LEED standards is one of the five environmental categories created to provide comfort, well-being, and productivity of occupants. The LEED IEQ category addresses design and construction guidelines, especially indoor air quality (IAQ), and thermal and lighting quality. IAQ seeks to reduce volatile organic compounds (VOCs), and other air impurities such as microbial contaminants. Buildings rely on a properly designed HVAC system to provide adequate ventilation and air filtration as well as isolate operations (such as kitchens and dry cleaners) from other occupancies. During the designing and constructing processes, choosing construction materials and interior finish products with zero or low emissions will improve IAQ. Many building materials and cleaning/maintenance products emit toxic gases such as VOCs and formaldehyde. These gases can have a detrimental impact on occupants' health as well as productivity. Avoiding these products will increase IEQ of a building. Personal temperature and airflow control over the HVAC system coupled with a properly designed building envelope will also aid in increasing the thermal quality of a building. Creating a high luminous environment performance through the careful integration of natural and artificial light sources will improve the lighting quality of a structure.

\section{OPERATIONS AND MAINTENANCE OPTIMIZATION}

Ensuring operation and maintenance (O\&M) personnel are parts of the project planning; thus development process will help retain the green criteria designed at the onset of the project. Every aspect of GB is integrated into the O\&M phase of a building life. The addition of new green technologies also falls on the O\&M staff. Although the goal of waste reduction may be applied during the designing, constructing, and demolishing phases of a building life cycle, the green practices such as recycling and air quality enhancement take place in the O\&M phase.

\section{WASTE REDUCTION}

The green architecture also seeks to reduce waste of energy, water, and materials used during construction. For example, in California, nearly $60 \%$ of the state waste comes from commercial buildings. During the construction phase, one goal should be used to reduce the amount of material going to landfills. Well designed buildings also help to reduce the amount of waste generated by the occupants through providing on-site solutions such as compost bins to reduce matter going to landfills.

Several options exist to reduce the impact on wells or water treatment plants. Grey water, 
which is wastewater from sources such as dishwashing or washing machines can be used for subsurface irrigation or if treated for nonpotable purposes; e.g., to flush toilets and wash cars. Rainwater collectors are used for similar purposes.

Centralised wastewater treatment systems can be costly and use a lot of energy. An alternative to this process is by converting waste and wastewater into fertiliser, which helps to avoid these costs and shows other benefits. Liquid fertiliser can be produced by collecting human waste at the source and running it to a semicentralised biogas plant with other biological waste. Practices like these provide soil with organic nutrients and create carbon sinks that remove carbon dioxide from the atmosphere, which offset greenhouse gas emission

\section{PROPOSED FRAMEWORK}

\section{CONCEPTUAL}

Figure 2 illustrates the framework implementation of GB design for Malaysian government building derived from the analytical literature review which consists of the phases of concept process and also in depth review conducted from previous studies. This framework consists of five factors involving project management procedures, building design procedures, government policies, type of project execution (design and build), and project staff perceptions.

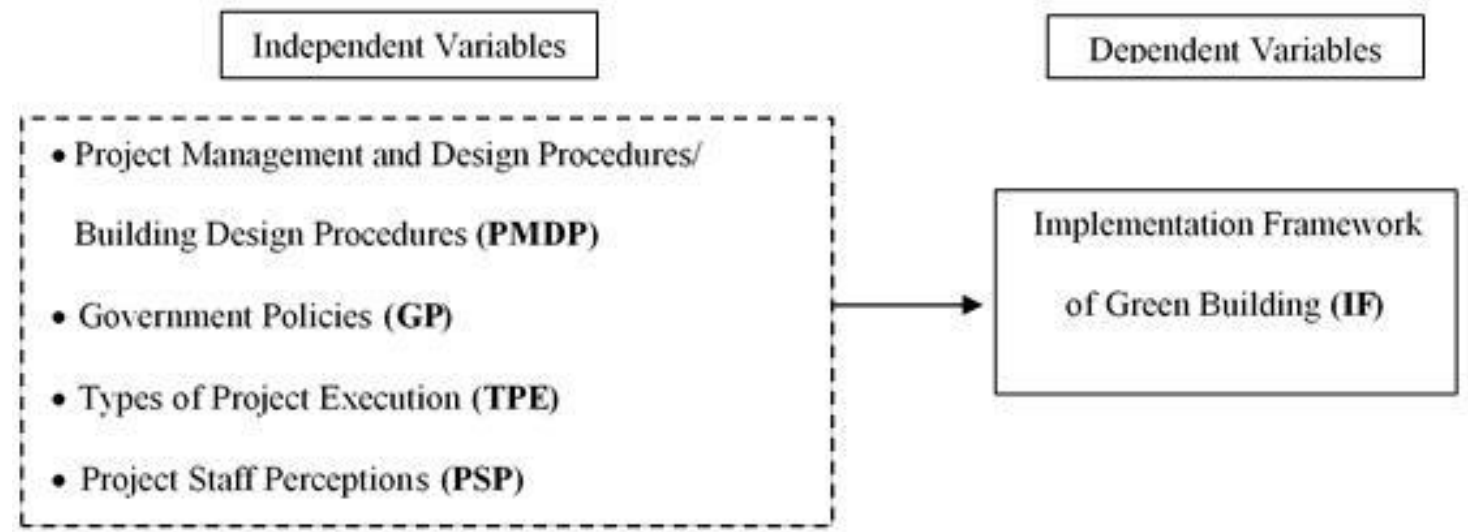

Figure 2 Proposed Conceptual Framework

\subsection{PILOT TEST}

A pilot test was conducted on 12 April 2015 to test for reliability and validity of the instrument while inferential analysis to test the hypothesis that has been developed. The pilot test was conducted with 30 respondents selected among multilevel of project teams including engineers, architects, quantity surveyor, assistants engineers, technical assistant, stake holders, contractors and consultants from MKR Project Team, , 'Cawangan Kerja Bangunan Am', PWD Headquarters Kuala Lumpur. All the returned questionnaires were reviewed accordingly to ensure all the questions were not left unanswered.

\subsection{DEMOGRAPHIC OF RESPONDENTS}

The results of the demographic information collected from the survey questionnaire are illustrated in Table 1. Most of the respondents were male $(63.3 \%)$ and female $(36.7 \%)$. Age wise, the highest was recorded among 25 to 40 years old with $76.7 \%$ followed by $41-56$ years with $13.3 \%, 19-24$ years old with $6.7 \%$, and 57 to 60 years old with $3.3 \%$. The majority of the respondents were professionals that made up $63.3 \%$ followed by supporting staff with $23.3 \%$ and management with $13.3 \%$. In terms of race, most of the respondents were Malay which made up $90 \%$ and Indian 10\%. Most of the respondents' level of education was from the universities with $73.3 \%$, others $16.7 \%$, primary school $3.3 \%$, and secondary school $6.7 \%$. A small proportion of the "others" was workers with no education and did not attend any university. Even though there were eight respondents who had only primary school education, secondary school, and 'others' education, they were part of the project team. In other words, they were fully directly involved in supervision and managing the MKR project; thus, it could be inferred that they had high knowledge and experiences in conducting and implementing the GB project to answer the questionnaires.

Table 1 Demographic Profile of Respondents

\begin{tabular}{llcc}
\hline \multicolumn{1}{c}{ Variables } & Sub- Variables & Frequency & $\begin{array}{l}\text { Percentage } \\
(\%)\end{array}$ \\
& & & \\
\hline Designation & Professionals & 19 & 63.3 \\
Grade & Management & 4 & 13.3 \\
& Supporting Staff & 7 & 23.3
\end{tabular}




\begin{tabular}{llll} 
Age & $19-24$ & 2 & 6.7 \\
(years) & $25-40$ & 23 & 76.7 \\
& $41-56$ & 4 & 13.3 \\
Gender & $57-60$ & 1 & 3.3 \\
& Male & 19 & 63.3 \\
& Female & 11 & 36.7 \\
Race & Malay & 27 & 90 \\
& Chinese & 0 & 0 \\
& Indian & 3 & 10 \\
& Primary & & \\
& School & 1 & 3.3 \\
& Secondary & 2 & 3.7 \\
& School & 22 & 73.3 \\
& Universities & 5 & 16.7 \\
\hline & Others & & \\
\hline
\end{tabular}

\subsection{PILOT TEST DATA ANALYSIS}

The data for the pilot test were analysed using IBM SPSS version 22.0. The technique used involved descriptive and inferential analyses. The descriptive analysis consists of percentage and frequency of the respondent feedbacks and strength for every variable. Meanwhile, the inferential analysis used the Pearson correlation technique. Besides that, the coding and recoding processes of the data are essential before the data analysis was conducted.

\subsubsection{RELIABILITY TEST ANALYSISFOR MKR PROJECT PILOT TEST}

The data collected were put under a series of tests to fulfil the study needs. A reliability test was conducted due to its ability in showing how loose the questionnaires were from the random error and determining the data validity (Wells \& Wollack, 2003). By using the internal consistency, it determines the degree of the whole items that made up the scale and measured under the same underlying attributes. The most common method used for measuring it is by using Cronbach's coefficient alpha. The test value will increase as the correlations between the test items increase. The reliabilitytest performed for each section in the questionnaire and the result are illustrated in Table 2. The result shows that the Cronbach's alpha for the whole items was 0.982 . Thus, the variable and its items were considered reliable to be preceded and tested for the hypothesis and research requirements.

Table 2 Reliability Statistics

$$
\text { Cronbach's Alpha } \quad \mathrm{N} \text { of items }
$$

\section{0}

\subsubsection{HYPOTHESIS TESTING FOR MKR PROJECT PILOT TEST STUDY}

Five hypotheses were developed to elaborate all the pertaining relationships between all the independent variables and dependent variables in the theoretical framework. The hypotheses statements are shown in Table 3.

Table 3 Hypotheses statements developed in the theoretical framework.

\begin{tabular}{ll}
\hline Research Hyphothesis & $\begin{array}{l}\text { Statistical } \\
\text { Analysis }\end{array}$ \\
\hline $\begin{array}{l}\text { Hyphothesis 1: There is a significant } \\
\text { relationship between project management } \\
\text { procedures/ guidelines and implementation }\end{array}$ & $\begin{array}{l}\text { Pearson } \\
\text { of Green Building }\end{array}$ \\
\hline
\end{tabular}

Hyphothesis 2: There is a significant

relationship between Building design procedures/guidelines and implementation Correlation of Green Building

Hyphothesis 3: There is significant relationship between Government policies Pearson and implementation of Green Building

Hyphothesis 4: There is a significant relationship between types of project execution and implementation of Green

Pearson Building

Hyphothesis 5: There is significant relationship between project staff perception Pearson and implementation of Green Building Correlation

\subsection{DESCRIPTIVE ANALYSIS OF THE VARIABLES}

The items of each independent variable were analysed descriptively while the mean scores were used to verify the degree of agreement of the variables. Table 4 illustrates the results from the descriptive analysis conducted on all the independent variables. Each variable was coded as project management and design procedures (PMDP) with 23 items (from PMDP1 to PMDP 23), GP with 4 items (from GP1 to GP4), TPE with 14 items (from TPE1 to TPE14) and PSP with 9 items (PSP1 to PSP9). The five-point scale used for the questions was ranging from $1=$ strongly agree to $5=$ strongly disagree. The mean score for PMDP variable was recorded as 2.51 , which can be interpreted as most of the respondents agreed or feeling neutral on items asked in the questionnaire. The respondents were asked questions such as whether the GB implementation in their organisation pursuing GBI from the Malaysia Green Building Confederation (MGBC), whether GB project implementation was designed to achieve the GBI rating, whether the GB project implementation in their organisation utilises a whole building energy model or renewable energy technologies . Based on the mean score, most of the respondents agreed that the GB project implementation in their organisation is utilising every aspect of GB in terms of energy, sensors, consumption, preservation, and minimising heat effect, recycling, and encouraging and promoting green renovation or technology. 
GP variable recorded an overall mean score of 2.54 which showed that most of the respondents agreed with each of the questions asked. The respondents were asked questions such as whether the GB project implemented by their organisation utilise Project Management Body of Knowledge (PMBOK), PWD scale system and Quality Management System, and National Green Technology Policy of Malaysia (NGTP).

As for TPE variable, the overall mean score was recorded as 2.51 which also meant for agreement on the entire questions being asked. Some of the questions asked were on their preference of which individual, government, society, NGO and private organisation gives the best options for solving the environmental problems and how PWD Malaysia plays an important role in implementing the green government project in the Malaysian government building.s.

PSP variable recorded an overall mean score of 2.21 that signified the agreement among the respondents on the questions asked. It showed that most of the respondents were aware of GB and its importance towards the environment and how matters such as waste management, energy and water efficiency, occupancy health, and conserving natural resources played an important factor for GB. The respondents were also hard to disagree when they were asked on how GB contributes to cost-saving, environment-friendly, and energy usage of the project.

Table 4 Descriptive Results of the Variables

\begin{tabular}{|c|c|c|c|c|c|}
\hline Code & Mean & $\begin{array}{c}\text { Std. } \\
\text { deviation }\end{array}$ & Code & Mean & $\begin{array}{c}\text { Std. } \\
\text { deviation }\end{array}$ \\
\hline PMDP1 & 2.5333 & 1.22428 & GP3 & 2.5000 & 0.97379 \\
\hline PMDP2 & 2.3667 & 1.21721 & GP4 & 2.5000 & 1.16708 \\
\hline PMDP3 & 2.3000 & 1.23596 & TPE1 & 2.4333 & 1.13512 \\
\hline PMDP4 & 2.3333 & 1.09334 & TPE2 & 2.3333 & 1.06134 \\
\hline PMDP5 & 2.6000 & 1.03724 & TPE3 & 2.6000 & 1.03724 \\
\hline PMDP6 & 2.5000 & 1.10641 & TPE4 & 2.3333 & 1.06134 \\
\hline PMDP7 & 2.5333 & 0.93710 & TPE5 & 2.2333 & 1.00630 \\
\hline PMDP8 & 2.5667 & 0.93526 & TPE6 & 2.5667 & 1.00630 \\
\hline PMDP9 & 2.1667 & 0.98553 & TPE7 & 2.6000 & 1.06997 \\
\hline PMDP10 & 2.5000 & 1.04221 & TPE8 & 2.4000 & 1.00344 \\
\hline PMDP11 & 2.7333 & 1.01483 & TPE9 & 2.9000 & 1.06188 \\
\hline PMDP12 & 2.6333 & 1.12903 & TPE10 & 2.6000 & 0.93218 \\
\hline PMDP13 & 2.2667 & 0.90719 & TPE11 & 2.3333 & 0.99424 \\
\hline PMDP14 & 3.0333 & 1.95613 & TPE12 & 2.6000 & 1.03724 \\
\hline PMDP15 & 2.7333 & 1.14269 & TPE13 & 2.7667 & 1.04000 \\
\hline PMDP16 & 2.4667 & 1.07425 & TPE14 & 2.5000 & 1.13715 \\
\hline PMDP17 & 2.8000 & 1.06350 & PSP1 & 2.2000 & 1.21485 \\
\hline PMDP18 & 2.7333 & 1.11211 & PSP2 & 2.2000 & 1.06350 \\
\hline PMDP19 & 2.5333 & 0.89955 & PSP3 & 2.0667 & 1.25762 \\
\hline PMDP20 & 2.2000 & 1.12648 & PSP4 & 1.9333 & 1.14269 \\
\hline PMDP21 & 2.2333 & 1.10433 & PSP5 & 2.3333 & 1.15470 \\
\hline PMDP22 & 2.5333 & 1.04166 & PSP6 & 2.2000 & 1.12648 \\
\hline PMDP23 & 2.5333 & 0.97320 & PSP7 & 2.7000 & 1.14921 \\
\hline GP1 & 2.6000 & 0.96847 & PSP8 & 2.3000 & 1.05536 \\
\hline GP2 & 2.5667 & 0.93526 & PSP9 & 2.1333 & 1.00801 \\
\hline
\end{tabular}




\subsection{CORRELATION ANALYSIS}

In order to understand the strength of the correlation existed between two or more variables, a correlation analysis was used to test the data. All variables involved in the study were tested. The results are presented in Table 5 below. In Table 5, the correlations between all the variables were statistically significant. There was a highly significant correlation between PSP and TPE, PMDP, and IF itself. However, GP seemed to be a moderate but significant correlation with all variables and high and significant correlation with the IF.

Table 5 Pearson Correlation Matrix for Study Variable

\begin{tabular}{|c|c|c|c|c|c|c|}
\hline & & PSP & TPE & PMDP & GP & IF \\
\hline \multirow[t]{3}{*}{$\overline{\text { PSP }}$} & Pearson & 1 & $0.884^{* *}$ & $0.839^{* *}$ & $0.489^{* *}$ & $0.921^{* *}$ \\
\hline & Correlation & & & & & \\
\hline & $\begin{array}{l}\text { Sig. (2- } \\
\text { tailed) }\end{array}$ & & 0.000 & 0.000 & 0.006 & 0.000 \\
\hline \multirow[t]{2}{*}{ TPE } & Pearson & & 1 & $0.940^{* *}$ & $0.484^{* *}$ & $0.942^{* *}$ \\
\hline & $\begin{array}{l}\text { Sig. (2- } \\
\text { tailed) }\end{array}$ & & & 0.000 & 0.007 & 0.000 \\
\hline \multirow[t]{3}{*}{ PMDP } & Pearson & & & 1 & $0.480^{\text {** }}$ & $0.925^{* *}$ \\
\hline & Correlation & & & & & \\
\hline & $\begin{array}{l}\text { Sig. (2- } \\
\text { tailed) }\end{array}$ & & & & 0.007 & 0.000 \\
\hline \multirow[t]{3}{*}{ GP } & Pearson & & & & 1 & $0.709^{* *}$ \\
\hline & Correlation & & & & & \\
\hline & $\begin{array}{l}\text { Sig. (2- } \\
\text { tailed) }\end{array}$ & & & & & 0.000 \\
\hline \multirow[t]{3}{*}{ IF } & Pearson & & & & & 1 \\
\hline & Correlation & & & & & \\
\hline & $\begin{array}{l}\text { Sig. (2- } \\
\text { tailed) }\end{array}$ & & & & & \\
\hline$* *$ Corre & lation is sign & ficent & at the 0.0 & 1 level ( & 2-tailed) & \\
\hline
\end{tabular}

\subsection{REGRESSION ANALYSIS}

The data were then analysed using the linear regression method. The analysis was deemed as necessary in order to confirm the relationship existed between the independent and dependent variables as suggested in the hypothesis. The results will be able to clarify whether the independent variable significantly influences the dependent variable. The regression test result for all hypotheses is illustrated in Table 6.

Table 6 Model Summary

\begin{tabular}{|c|c|c|c|c|}
\hline Hypothesis & $\mathrm{R}$ & $\mathrm{R}^{2}$ & $\begin{array}{l}\text { Standard } \\
\text { Error } \\
\text { of the } \\
\text { Estimate }\end{array}$ & $\begin{array}{l}\text { Strength } \\
\text { of } \\
\text { association } \\
\text { with IF }\end{array}$ \\
\hline 1 & 0.925 & 0.856 & 0.02390 & High \\
\hline 2 & 0.925 & 0.856 & 0.02390 & High \\
\hline 3 & 0.709 & 0.502 & 0.04439 & Moderate \\
\hline 4 & 0.942 & 0.887 & 0.02119 & High \\
\hline 5 & 0.921 & 0.849 & 0.02446 & High \\
\hline
\end{tabular}

In Table 6, for hypotheses 1 and 2 , the $\mathrm{R}^{2}$ which showed the degree of predictive accuracy of the regression model in explaining the variation of the dependent variable was recorded as 0.856 which meant that $85.6 \%$ of the independent variables attributed to PMDP in influencing IF. This is considered to be good because it showed that only $14.4 \%$ of other variables could not be covered in this research and thus provided opportunities for more research to be conducted in the area. There was a positive and significant relationship between both variables and a beta coefficient value of $\beta=.925$ was produced. Some researchers have stated that the early introduction of the intention to develop the GB projects by implementing project management and building design guidelines came from the project owner (Olanipekun et al., 2017). This fact was supported by Korkmaz et al. (2010) who suggested that the project owners should introduce their intention to develop GB projects at the pre-designing stage. It indicates that the factor of project management and policies guidelines should be introduced and significant for the further intention of developing $\mathrm{GB}$ project in Malaysia. Therefore, the authors concluded that hypotheses 1 and 2 were significantly supported by the results of linear regression and also the literature findings.

For the third hypothesis, $\mathrm{R}^{2}$ of 0.502 showed that there were still $49.8 \%$ of the independent variables of GP not covered in the research. A beta coefficient value of $\beta=0.709$ was recorded which could be interpreted as the level of impacts by the variable on the framework implementation of the GB. The relationship between the variable was positive and significant $(<0.01)$. This finding was supported by Darko and Chan (2016) who reported that most governments are currently governing or planning to administer market activities through the promulgation of legislations and national public GB policies (such as mandatory minimum energy-efficiency standards). In other words, the implementation of GP on the GB projects involving either governmental or nongovernmental group is becoming the catalyst to the environmental sustainability development. However, GP is not the key factor for the success of GB projects but the participants involved in the GB projects who contributed to the development of the GB. Palanisamy and Klotz (2011) also stated that the knowledge in a GB project is a key factor to develop a related industrial building project in India; thus, a thorough understanding of GP on the GB projects is also needed to deliver them in Malaysia. In addition, Darko and Chan (2016) also reported that the developed economies or developing countries also made good efforts to promote the GB research and contributed to the 
success of GB projects. It indicates that GP plays the role to deliver the GB projects.

Hypothesis 4 of the study showed that $88.7 \%$ of the variation in TPE influenced IF. The relationship between the variables was recorded as positive and significant $(<0.01)$ with a beta coefficient value of $\beta=.942$. In the early stages, the project owner is responsible to define the types of project execution whether to introduce the intention to develop GB projects or not. Robichaud \& Anantatmula (2010) stated that project owners should define in the early stage of the intention to develop GB projects from the setting project goals as early as prior to selecting a site and initiating design. However, the execution of projects in early stages may be difficult for the project participants to implement the project goal. Even though the project owner clearly defines that the upcoming projects must be in line with the GB characteristics, the knowledge of project participants has become a barrier to deliver the ideal project. It indicates that the education of project participants should be parallel with the project owner on the project execution to achieve the goal of the project. However, the implementation of $\mathrm{GB}$ in the commercial/government building should be applicable in the development industry. In terms of economy, the GB contributes to building stakeholders by enhancing health and productivity, reducing environmental impact, using environmentally effective materials, and lowering electric and water utility costs (Vyas \& Jha, 2017). It indicates that the TPE factor should be considered in the implementation of GB as it is parallel to the aim by the Malaysian government to reduce the GHG emissions from building industry. In conclusion, TPE is the main factor to implement the GB; thus, it benefitted the ideal implementation of $\mathrm{GB}$ in the development of commercial/government building for the environmental sustainability.

Other than that, the result showed that $84.9 \%$ of the PSP attributes influenced IF. The relationship between the variables was recorded as positive and significant $(<0.01)$ with a beta coefficient value of $\beta=.921$. This result is deemed to be good since it indicated that about $15.1 \%$ left of other attributes that were not covered in this study thus provided an opportunity for future research in the area. The project staff or participants, who possessed the suitable experiences and capabilities were the performance indicator for GB projects (Love et al., 2012). In other words, the GB knowledge possessed by all participants involved in the GB projects is the main indicator for the framework implementation in the GB projects. This could also be possible by participating in the selection of project participants who have capabilities for collaboration, thereby allowing for the whole system thinking and seamless sharing of information during the delivery of GB projects (Olanipekun et al., 2017). In a different approach, the project owner should emphasis on the environmental criterion as the basis for selecting GB project participants (Li et al. 2012). Therefore, the project staff perceptions including the project owner significantly promote the delivery of GB project performance.

\section{CONCLUSION}

In conclusion, the pilot test results on MKR showed that there were indeed positive and significant relationships between each of independent variables (PMDP, GP, TPE, and PSP) and dependent variable (IF). In this work, the authors proposed that the new framework of the GB project implementation in Malaysia should take into account these independent variables. This implementation framework significantly contributed remarkable impacts on the existence of the implementation of GB in Malaysia as well as served as a basic platform for other government agencies in Malaysia. Throughout this work, this framework can be an indicator to ensure the success of GB projects in Malaysia as proven by MKR, which was awarded the Platinum GBI. Based on the experiences of MKR, this new framework on GB projects in Malaysia was successfully developed and it may be proposed for implementing GB for the new projects in the future.

\section{ACKNOWLEDGEMENT}

This research is supported by Public Works Department of Malaysia. We also thank the University of Malaya for supporting this research.

\section{REFERENCES}

Adetokunbo, I., \& Emeka,M. (2015) .Urbanization, housing, homelessness and climate change adaptation in Lagos, Nigeria: Lessons from Asia. Journal of Design and Built Environment, 15(2).

Begum, R.A., \& Pereira, J.J. (2011). Corporate perceptions of climate change in Malaysia. Afr. J. Business Manag., 5, 4299-4305.

Darko, A., \& Chan, A.P.C. (2016). Critical analysis of green building research trend in construction journals. Habitat International, 57,53-63.

Green Building Index (GBI, 2017). Retrieved September 7, 2017, from the Green Building Index Website http://new.greenbuildingindex.org/ 
Kamaruzzaman, S.N., Eric, C.W.L., Zainon, N., Mohamed Zaid, N.S., \& Phui, F.W.(2016). Environmental assessment schemes for non-domestic building refurbishment in the Malaysian context. Ecological Indicators, 69, 548-558.

Korkmaz, S., Horman, M., Molenaar, K., \& Gransberg, D. (2010). Influence of Project Delivery Methods on Achieving Sustainable High Performance Buildings. Report on Case Studies. The Charles Pankow Foundation. Available at http://admin.dbia.org/resourcecenter/ Documents/CPF_ThrustII_052120 10_Final.pdf

Li, Y.Y. et al., (2012). Exploration of critical external partners of architecture/engineering/construction (AEC) firms for delivering green building projects in Singapore. Coll. Publishing, 7(3), 193-209.

Love, P.E.D., et al., (2012). Achieving the green building council of Australia's world leadership rating in an office building in Perth. J. Constr. Eng. Manag, 138(5), 652660.

Moghimi, S., Azizpour,F., Mat, S., Lim, C.H., Salleh, E., \& Sopian, K. (2014). Building energy index and end-use energy analysis in large scale hospitals - case study in Malaysia. Energy Efficiency, 7, 243-256.

Olanipekun, A.O. et al., (2017). Indicators of owner commitment for successful delivery of green building projects. Ecological Indicators, 72, 268-277.

Palanisamy, P., \& Klotz, L. (2011). Delivery process attributes, common to India and the US, for more sustainable buildings. Coll. Publishing, 6(4), 146-157.

Robichaud, L.B., \& Anantatmula, V.S., (2010). Greening project management practices for sustainable construction. J. Manage. Eng., 27(1), 48-57.

Shika, S.A. et al., (2010). Towards an Integrative Sustainability Concept for Retrofitting Commercial Office Buildings in Malaysia

The Star Online (2016). Build homes by going green. Retrieved August 20, 2017, from The Star Online Website http://www.thestar.com.my/news/nation/2 016/12/08/build-homes-by-going-

greennajib- save-time-and-money-byusingmore- efficient-methods/

Vyas, G.S. \& Jha, K.N. (2017). Benchmarking green building attributes to achieve cost effectiveness using a data envelopment analysis. Sustainable Cities and Society, 28, 127-134. Available at: http://linkinghub.elsevier.com/retrieve/pii/ S2210670716303 